Do Immigrants Work IN Riskier Jobs?

Pia M. Orrenius and Madeline Zavodny

Research Department

Working Paper 0901

Federal Reserve Bank of Dallas 


\title{
Do Immigrants Work in Riskier Jobs?*
}

\author{
Pia M. Orrenius \\ Federal Reserve Bank of Dallas and IZA \\ pia.orrenius@dal.frb.org \\ Madeline Zavodny \\ Agnes Scott College and IZA \\ mzavodny@agnesscott.edu
}

January 2009

\begin{abstract}
Recent media and government reports suggest that immigrants are more likely to hold jobs with worse working conditions than U.S.-born workers, perhaps because immigrants work in jobs that "natives don't want." Despite this widespread view, earlier studies have not found immigrants to be in riskier jobs than natives. This study combines individual-level data from the 2003-2005 American Community Survey with Bureau of Labor Statistics data on work-related injuries and fatalities to take a fresh look at whether foreign-born workers are employed in more dangerous jobs. The results indicate that immigrants are in fact more likely to work in risky jobs than U.S.-born workers, partly due to differences in average characteristics, such as immigrants' lower English language ability and educational attainment.
\end{abstract}

JEL Classification: J81, J61, J24, J28

Keywords: working conditions, immigrants, job injuries

* The authors thank participants at the 2008 Population Association of America, Society of Labor Economists, and IZA Annual Migration Meeting conferences for helpful comments. Madeline Zavodny thanks the Chief Justice Earl Warren Institute for Race, Ethnicity, and Diversity, Boalt Law School, University of California, Berkeley, for financial support. The views expressed here are those of the authors and do not necessarily reflect those of the Federal Reserve Bank of Dallas or the Federal Reserve System. Madeline Zavodny will provide data and coding information to those wishing to replicate the study. 


\section{Do Immigrants Work in Riskier Jobs?}

Stylized facts suggest that the foreign-born are more likely to work in risky jobs than natives. ${ }^{1}$ For example, immigrants are disproportionately employed in agriculture and construction, sectors with relatively high injury and fatality levels. Moreover, immigrants may be in riskier jobs or perform riskier tasks than natives within those sectors. Anecdotal evidence supports this possibility. For example, 21 of 29 fatal construction accidents in New York City during a recent 12-month period involved workers who were immigrants or had limited English proficiency (Chan 2006). Studies of immigrants doing reconstruction work in New Orleans after Hurricane Katrina suggest that large numbers of both documented and undocumented foreignborn workers were exposed to dangerous substances and conditions (Fletcher et al. 2006). Nationally, the proportion of work-related fatalities among foreign-born Hispanic workers rose from 1992 to 2006 (CDC 2008) and fatal work injuries among foreign-born Hispanic workers reached a series high in 2005 (Bureau of Labor Statistics 2006), making this issue a pressing public policy concern. This study therefore examines whether immigrants are indeed more likely than natives to work in risky jobs, as measured by industry and occupation injury and fatality rates, and investigates the causes of any such differences.

\section{BACKGROUND}

Stories of immigrants injured or killed while working in dangerous jobs abound. Dramatic recent examples include: Two Ecuadorian brothers who worked as window washers in New York fell 47 stories when their scaffolding collapsed. One died and the other was gravely injured

\footnotetext{
${ }^{1}$ We use the terms immigrant and foreign-born interchangeably here to refer to all individuals born outside the U.S. to parents who are not U.S. citizens except when distinguishing between illegal (undocumented) immigrants and other immigrants (which here includes naturalized citizens, legal permanent residents, and legal temporary migrants).
} 
(McFadden and Schweber 2007). A migrant farm worker died of heat stroke after picking tobacco in 110 degree weather in North Carolina. His internal body temperature was recorded at 108 degrees (NIOSH 2007). A 14-year-old undocumented worker was partially decapitated and crushed by machinery in a plant in Tennessee. The youth, who had presented forged documents indicating that he was 19 years old, had received no safety training (NIOSH 2005). Over 3000 foreign-born workers were murdered on the job between 1992 and 2005, making homicide the leading cause of workplace fatalities among immigrants (Franklin and Little 2006).

There are several reasons why immigrants might hold riskier jobs than natives. First, immigrants might have different perceptions or knowledge of job risks than natives. Immigrants may perceive work-related risks differently than natives because job conditions in the U.S. may be less risky than those in some developing countries, for example. Immigrants might therefore be more willing than natives to take risky jobs because they do not perceive them as particularly dangerous. Research has not explicitly examined this hypothesis.

In addition, lower levels of education, social capital, and English ability may lead to immigrants' having less information about job risks. Sandy and Elliott (1996) and Bender, Mridha, and Peoples (2006) note that employers may understate workplace risks to workers; this understatement may occur more among employers who hire immigrants, either intentionally or because of communication difficulties with immigrants who speak a different language. About $32 \%$ of foreign-born adults (aged 25 and older) in the U.S. do not have a high school diploma or equivalent, compared with $11 \%$ of natives (Census Bureau 2006), and about $83 \%$ of immigrants speak a language other than English at home, with 35\% of those reporting speaking English not well or not at all (Grieco 2003). These lower average levels of education and English ability could result in immigrants being less able to understand job risks. 
Immigrants may also end up in riskier jobs because they have few alternatives, particularly those who lack legal documents. As noted by the CDC (2008), the foreign born may be more willing to perform tasks with higher risk and more hesitant to decline such tasks for fear of losing their jobs. Loh and Richardson (2004) similarly comment that poor English ability and low education levels may limit many immigrants' employment options. A survey of immigrants in Chicago concluded that undocumented immigrants are more likely than legal immigrants to say that their working conditions are unsafe (Mehta et al. 2002). Previous research also indicates that undocumented immigrants are generally a complement to natives rather than a substitute, indicating that undocumented immigrants and natives work in different jobs (Bean, Lowell, and Taylor 1988). Undocumented immigrants are particularly overrepresented in agricultural, cleaning, construction, and food preparation jobs (Passel 2006), which involve more dangers than typical white-collar jobs. Undocumented workers working in the meat and poultry industries hold the "most dangerous factory jobs" in America and are subject to many abuses from their employers (Compa and Fellner 2005: A19). Workers in meatpacking and poultry processing jobs experience cuts, carpel tunnel syndrome, skin diseases, amputations, and even death.

Even if immigrants and natives had similar knowledge about job risks and the same legal status, immigrants might still occupy riskier jobs than natives because of differences in risk preferences or income. Immigrants may be more willing to take risky jobs because they tend to have lower incomes and less wealth than natives. Job amenities, including workplace safety, are usually viewed as a normal good, for which quantity demanded increases with wealth (Viscusi 1978). Because immigrants have less wealth than natives, on average (Cobb-Clark and Hildebrand 2006), they "buy" lower levels of job amenities. In other words, immigrants may be 
more willing than natives to trade off higher wages for worse conditions. ${ }^{2}$ In addition, Berger and Gabriel (1991) point out that immigrants may be less risk averse than natives, as evidenced by the fact that they were willing to take on the risk of migrating to the U.S. ${ }^{3}$

The "healthy immigrant effect" also might result in immigrants holding riskier jobs than natives. Immigrants tend to be healthier upon arrival than natives, although this health advantage dissipates over time (Antecol and Bedard 2006, and references therein). Immigrants, particularly recent ones, therefore might hold more physically strenuous jobs than natives. These physically strenuous jobs, which are prevalent in sectors like construction, meatpacking, and agriculture, may involve more workplace risks. No previous research has documented this link, however.

Despite media reports, anecdotal evidence, and theoretical implications that immigrants work under more hazardous conditions, previous research that combines the distribution of workers across industries with industry-level fatality or injury rates has not found that immigrants work in riskier jobs than natives. Combining 1980 Census data with industry fatality data, Berger and Gabriel (1991) compare sample means and report that immigrants are employed in industries with lower average fatality rates. Hamermesh (1998) similarly combines 1991 Current Population Survey data with industry injury rates. He finds that immigrants are not more likely than white natives to work in industries with higher injury rates. Hamermesh's result holds both in sample means and in regression estimates controlling for age, education, and the like.

More recent studies that directly examine work-related deaths reach the opposite conclusion. An analysis of work-related fatalities data for the period 1996-2001 by Loh and Richardson (2004) indicates that work-related fatality rates are higher among the foreign-born

\footnotetext{
${ }^{2}$ This assumes that riskier jobs pay more, which is generally true for jobs with higher fatality rates but not for jobs with higher injury rates, as noted by Rosen (1986), Smith (1979), and Viscusi (1993).

${ }^{3}$ However, Bonin et al. (2008) show that — controlling for age, education, and the like - foreign nationals living in Germany but born abroad self-report lower willingness to take risks, including with regard to career, than German nationals or foreign nationals living in Germany who were born in Germany. Bonin et al. (2006) report that the immigrant-native gap in risk proclivity shrinks as immigrants assimilate into German society.
} 
than among natives, with fatalities particularly high among immigrants from Mexico. Supporting this conclusion, Richardson, Ruser, and Suarez (2003) note that foreign-born Hispanic workers had higher fatality rates during 1995-2000 than both Hispanic and non-Hispanic native-born workers. The higher fatality rate among foreign-born Hispanics mainly arises from their disproportionate employment in construction and agriculture, industries with relatively high fatality rates. Death rates due to workplace homicides are also higher among the foreign-born, particularly among Asians (because of robberies at retail stores), than among natives (Sincavage 2005).

The divergent conclusions reached by previous studies could be due to methodological differences. Hamermesh (1998) and Berger and Gabriel (1991) merge industry injury and fatality rates with individual level-data. Loh and Richardson (2004) and Richardson, Ruser, and Suarez (2003), in contrast, simply report the number of work-related deaths per worker. Immigrants might work in industries with lower fatality rates but be more likely to experience fatalities within industries, resulting in higher overall fatality rates for immigrants. The foreign born might perform riskier tasks than natives within a given industry. Dong and Platner (2004) report that Hispanic construction workers—over $70 \%$ of whom are foreign-born—have higher fatality rates than non-Hispanics within several specific occupations (such as roofers).

Changes over time are another potential explanation for the differing conclusions reached by previous research. Immigrants might work in riskier jobs more now than previously. Potential explanations for a relative increase in immigrants' job risk include a relative decline in average human capital among immigrants and crowding of immigrants into riskier jobs as the immigrant population has risen over time. In particular, immigrants have moved into the construction sector in large numbers since the early 1990s, and construction activity surged after 1997 as interest 
rates fell and the economy boomed. In addition, continued mass immigration may have contributed to deteriorating working conditions in jobs that primarily employ immigrants.

To explore whether immigrants hold riskier jobs than natives, we combine data on the distribution of foreign- and native-born workers across industries and occupations with industryand occupation-level data on work-related injuries and fatalities in the U.S. during 2003-2005. In essence, we use the same technique as Berger and Gabriel (1991) and Hamermesh (1998) but more recent data. Our analysis thus updates their results. Like Hamermesh, we examine the role of observable characteristics, such as education and years since migration, in whether workers hold risky jobs. Our analysis also adds a measure of workers' ability to speak English, a characteristic not available in Hamermesh's data. The sample means indicate that during 20032005 immigrants were disproportionately employed in industries and occupations with high injury and fatality rates, and immigrants worked in industries with higher fatality rates and occupations with higher injury rates even after controlling for a wide variety of observable characteristics. Our results mark a change from Hamermesh's (1998) injury results for 1991 and Berger and Gabriel's (1991) fatality results for 1980. Poor English ability and lower average levels of education appear to play key roles in the over-representation of immigrants in risky jobs.

\section{DATA AND METHODS}

We use two main data sources for the period 2003-2005: individual-level data from the American Community Survey (ACS), and data on work-related fatalities and nonfatal injuries and illnesses from the Bureau of Labor Statistics (BLS) injuries, illnesses, and fatalities (IIF) program. 
The ACS is a nationwide survey administered by the Census Bureau that asks about individual demographic and socioeconomic characteristics on an annual basis. The ACS was designed to replace the long form of the decennial Census and, in essence, asks the same questions as the 2000 Census long form. We focus on a national comparison of all foreign- and U.S.-born individuals aged 16 and older who report being employed in the private sector last week. ${ }^{4}$ The ACS reports detailed industry and occupation for these workers as well as characteristics such as age, education, and place of birth.

We define U.S. natives as people born in the U.S. or those born abroad to U.S. citizens. Immigrants are all people born outside of the U.S., regardless of their visa or citizenship status, who were not U.S. citizens at birth. "Immigrants" in the ACS thus encompasses naturalized citizens, legal permanent residents, temporary migrants, and (as discussed more below) undocumented immigrants. We do not include people born in U.S. territories or outlying areas (e.g., Puerto Rico) in our analysis because these people are U.S. citizens by birth but have very different characteristics than other U.S. natives. The ACS asks respondents who report speaking a language other than English at home to self-assess their ability to speak English as very well, well, not well, or not at all. The ACS also asks foreign-born people what year they came to live in the U.S. We use these answers to derive number of years of U.S. residence for immigrants.

\section{Injuries and Fatalities Data}

The fatalities data are from the Census of Fatal Occupational Injuries (CFOI) and include deaths resulting from traumatic events on the job. The BLS compiles the CFOI data by

\footnotetext{
${ }^{4}$ We do not include the self-employed because of concerns about whether they are included in the BLS IIF data. This may bias downward our results because excluding the self-employed drops day laborers (who are disproportionately employed in construction) and store owners (who are relatively frequent victims of workplace homicides). We do not include non-profit and government workers because the injury data are from the private sector.
} 
examining source records, such as death certificates, workers' compensation reports, and federal and state agency administrative reports. Deaths usually must be verified as work-related by at least two sources to be included in the CFOI. We do not focus on the primary fatal event (the event leading to the death, such as a fall) in this analysis; other studies show that homicide is the leading event for work-related fatalities among immigrants while highway incidents are the leading event among natives (Loh and Richardson, 2004). We focus instead on the number of fatalities, which is reported by industry and by occupation (not jointly by industry and occupation). We created fatality rates by dividing the number of fatalities by the number of private sector workers in that industry or occupation using data from the BLS Current Employment Statistics program for industry-level data or from the Occupational Employment Statistics for occupation-level data. ${ }^{5}$ Fatality rates are reported here as per 100,000 workers. The industries and occupations with the highest fatality rates are largely what one would expect. The industries with the highest fatality rates are fishing/hunting/trapping, taxi service, and logging. The occupations with the highest fatality rates include farmers and ranchers, fishers and hunters, loggers, and mining machine operators.

Figure 1 shows the trend in the overall fatality rate over the period 1992-2005. The fatality rate declined fairly steadily between 1994 and 2002 but leveled off in the last three years. The rate during 2003-2005 corresponds to an average of 5691 work-related deaths annually. The figure also shows the percentage of fatalities that occurred among foreign-born workers, which was reasonably stable at about $11 \%$ during $1992-1998$ but has since risen, reaching $18 \%$ in $2005 .^{6}$ This proportion exceeds the representation of immigrants in the labor force, which was

\footnotetext{
${ }^{5}$ Agricultural employment data are annual averages based on the Quarterly Census of Employment and Wages (QCEW).

${ }^{6}$ The overall fatality rates and number of work-related fatalities are from the IIF program. The number of workrelated deaths among foreign-born workers was compiled from unpublished data provided by the IIF program, Richardson (2005), and Seminario (2007). It bears noting that the IIF program classifies persons born abroad to U.S.
} 
about $15 \%$ in 2005 . Foreign-born workers thus appear to experience excess work-related mortality. During 2003-2005, about 960 foreign-born workers experienced a work-related death each year.

There are several factors underlying the substantial increase in the percentage of fatalities occurring to foreign-born workers after 1998. Loh and Richardson (2004) note that fatality rates rose for immigrants working in agricultural jobs and in manufacturing industries while fatality rates fell for natives. The increase coincides with a surge of immigrant inflows, particularly of undocumented immigrants, in the wake of economic crises in Latin America and with immigrants moving from the traditional agricultural sector to jobs in manufacturing and construction.

The increase also coincides with a construction boom fueled by low interest rates. During 1996-2001, nearly one in four fatally-injured foreign-born workers was employed in the construction industry, versus less than one in five natives (Loh and Richardson 2004). In 1994, about $10 \%$ of workers in the construction industry were foreign born, or about $6 \%$ of foreign born workers were employed in construction. By 2005 , immigrants accounted for about $22 \%$ of construction workers, and $12 \%$ of immigrants were working in the construction industry. This dramatic shift of immigrants into the construction sector seems likely to have played a large role in the rise in the immigrant share of work-related fatalities shown in Figure 1.

The nonfatal injuries and illnesses data are from the Survey of Occupational Injuries and Illnesses (SOII). The SOII data are based on reports collected annually from about 176,000 private industry establishments. ${ }^{7}$ The Occupational Safety and Health Administration (OSHA)

citizen parents as foreign-born individuals, which we do not. This discrepancy likely accounts for a very small number of workers, however (individuals born abroad to U.S. citizen parents are less than $1 \%$ of our ACS sample). ${ }^{7}$ Occupational injury and illness data for coal, metal, and nonmetal mining and for railroad activities are from the Department of Labor's Mine Safety and Health Administration and the Department of Transportation's Federal Railroad Administration. The SOII survey excludes all work-related fatalities as well as nonfatal work injuries and 
requires employers to keep logs of work-related injuries and illnesses, and the SOII data are based on these logs. Work-related injuries and illnesses included here involve at least one day away from work other than the incident day. These injuries may involve medical treatment (other than first aid), restriction of work or motion, loss of consciousness, or transfer to another job. Work-related illnesses are new cases recognized, diagnosed, and reported during the year. The BLS IIF program acknowledges that illnesses directly related to workplace activity are more likely to be reported than long-term latent illnesses, such as cancer. The SOII reports the total number of injuries and illnesses as well as by the nature of injury or illness, such as burns, fractures, and amputations. We focus on the total injury and illness rate but do report some results by nature of illness or injury. ${ }^{8}$ The BLS IIF program reports injury rates by industry but only levels for occupations; we converted the occupation data into rates as with the fatalities data. ${ }^{9}$ Injury rates are reported here as per 10,000 workers.

During 2003-2005, industry injury rates in our sample averaged 142 injuries per 10,000 workers while occupation injury rates averaged about 112. In levels, this corresponds to an average of 1,269,973 nonfatal injuries per year involving days away from work. Industries with the highest injury rates include bituminous coal underground mining, air transportation, and urban transit systems. The occupations with the highest injury rates, like those with the highest fatality rates, include farmers and ranchers, fishers and hunters, loggers, and mining machine operators.

illnesses to the self employed; to workers on farms with 10 or fewer employees; to private household workers; and to federal, state, and local government workers (http://www.bls.gov/iif/oshsum1.htm).

${ }^{8}$ For brevity, we refer to these data here as injury data, but the data include illnesses as well.

${ }^{9}$ The BLS IIF calculates the industry rates based on the number of full time equivalent workers. Because of data limitations, we calculated the occupation rates based on all workers, not full time equivalent workers. 


\section{Underreporting}

The BLS data likely underestimate the incidence of work-related injuries and illnesses (Azaroff, Levenstein, and Wegman 2002; Boden and Ozonoff 2008). There are several reasons for the undercount, including: workers might not report injuries or illnesses to their employers because they fear reprisal; workers might not be able to afford time away from work; and employers might not record and report all work-related injuries and illnesses in order to keep workers' compensation rates low and to avoid triggering inspections. Work-related fatalities also might be underreported by the CFOI, in part because at least two sources must verify the death as workrelated. The true extent of underreporting of both work-related fatalities and injuries is unknown.

Injuries and fatalities may be more likely to be underreported in industries and occupations that disproportionately employ immigrants. Immigrants, particularly the undocumented, may be less likely than natives to report a work-related injury or illness to an employer. Evidence on this issue is mixed. A survey of non-agricultural Latino immigrant workers in Alexandria, Virginia, found that all of those who had experienced a job-related injury had reported it to the employer, although most of them had not received any workers' compensation benefits (Pransky et al. 2002). A survey of unionized hotel room cleaners (mostly immigrants) in Las Vegas found that less than one-third who had experienced work-related pain had reported it to their employer (Scherzer, Rugulies, and Krause 2005). Underreporting also might occur at the firm level. Employers that hire large numbers of immigrants, particularly undocumented immigrants, might be less likely to follow OSHA record-keeping requirements for work-related injuries and illnesses. Similarly, it may be more difficult to verify a death as work-related for an immigrant worker, especially for undocumented immigrants.

If differential underreporting occurs, our results underestimate any immigrant-native differences. However, any bias due to differential underreporting is diluted by our use of 
industry- or occupation-level injury and fatality rates that combine immigrants and natives. If underreporting is more common for immigrant workers than for natives, the bias would be greater in rates stratified by nativity than in rates for all workers.

\section{Data Analysis}

We merge the ACS and IIF data by industry and, separately, by occupation. Industry is coded in both data sources using North American Industry Classification System (NAICS) codes, and occupation using the 6-digit "occsoc" codes. We used the most detailed level possible for merging the data sources by industry; if a match could not be made at the 4-digit NAICS level, we made it at the 3-digit level, and so on. Again, only workers in the private sector who are not self-employed are included here. We were able to match about $98 \%$ of these observations in the ACS to an industry or occupation injury or fatality rate. ${ }^{10}$

Immigrants account for over $14 \%$ of our sample. The immigrant sample in the ACS includes undocumented immigrants. A comparison of Department of Homeland Security (DHS) administrative records with the ACS suggests that the ACS includes a substantially larger population of foreign-born individuals than the DHS's estimate of legal permanent residents and temporary non-immigrants (Cornwell 2006; Hoefer, Rytina, and Campbell 2007). One potential reason for this is, of course, that the ACS includes at least some of the undocumented immigration population, which probably numbered around 11 million in 2005 (Passel 2006). However, like other large-scale government surveys, the ACS probably undercounts the undocumented population, particularly because it does not include people living in group quarters (Mather, Rivers, and Jacobsen 2005). The ACS likely undercounts the unauthorized

\footnotetext{
${ }^{10}$ The samples are slightly different depending on whether we examine industry or occupation injury or fatality rates, as indicated by the sample sizes shown in Table 2. Table 1 shows sample means of individual characteristics for all individuals included in any specification here.
} 
immigrant population by about 10\% (see Bean et al. 1998; Hanson 2006; and Hoefer, Rytina, and Campbell 2007).

Table 1 reports descriptive statistics for our sample. All of the immigrant-native differences in the weighted sample means are significant at the $1 \%$ level. Immigrants are more likely than natives to be male, married, Hispanic, and "other race" (which includes Asians and Pacific Islanders). Reflecting the bimodal distribution of education among immigrants, the percent of immigrants who do not have a high school diploma or equivalent is about 22 percentage points higher than among natives while the percent that have a college degree is similar for immigrants and natives. Almost all natives speak only English at home or report speaking English very well whereas immigrants' ability to speak English is quite varied.

Immigrants work in riskier industries and occupations. The sample means in Table 1 indicate that the average industry injury rate for immigrant workers is about 8 injuries per 10,000 workers higher than among native workers, and the average occupation injury rate is 31 injuries per 10,000 workers higher. The average industry fatality rate among immigrant workers is about 1.8 deaths per 100,000 workers higher than among natives, and the average occupation fatality rate is almost 1.6 deaths per 100,000 workers higher. These differences are probably downward biased by underreporting of injuries in industries that employ large numbers of immigrants, as discussed above. Our exclusion of government workers, who are disproportionately native-born and whose jobs tend to be less risky (except for the armed forces), and the self-employed also likely leads to an underestimate of immigrant-native differences.

As a first step in investigating why immigrants tend to work in riskier jobs, Table 2 presents sample means for the injury and fatality rates by education and English ability. All four measures are declining monotonically in education. Injury and fatality rates tend to improve with English ability, although all four measures are higher among workers who speak only English at 
home than among workers who speak another language at home but speak English very well. Workers who speak no English clearly face greater average injury and fatality rates than other workers.

\section{Regression Model}

The comparison of sample means in Tables 1 and 2 suggest that differences in education, English ability, or other individual characteristics may explain why immigrants tend to work in riskier jobs. We estimate ordinary least squares regressions of the determinants of injury and fatality rates to examine the extent of immigrant-native differences in average injury and fatality rates when controlling for other observable individual characteristics. The basic form of the regressions is

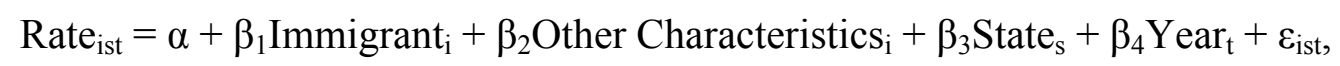

where the dependent variable is the injury or fatality rate in individual $i$ 's industry or occupation. The variable Immigrant is a dummy variable equal to 1 for immigrants and 0 for natives. The controls for Other Characteristics include a dummy variable equal to 1 for females, age and age squared, dummy variables for marital status (married and divorced/widowed/separated, with never married as the omitted category), dummy variables for race and ethnicity (black, other race, and Hispanic, with whites as the omitted category), and dummy variables for highest educational attainment (less than high school diploma, some college, or at least a college degree, with high school diploma as the omitted category). We also include a linear variable measuring years since moving to the U.S. (which equals 0 for all natives) and dummy variables measuring ability to speak English (very well, well, not well, and not at all, with speaking only English as 
the omitted category). The regressions also include fixed effects for state of residence and survey year. The coefficients on these fixed effects are not shown here. ${ }^{11}$ Observations are weighted using the person weights in the ACS. Standard errors are clustered on industry or occupation.

\section{RESULTS}

Controlling for observable individual characteristics reduces the immigrant-native differences in injury and fatality rates. Table 3 reports the regression results. The difference in the average industry injury rate falls from 8.19 injuries per 10,000 workers (based on the sample means in Table 1) to about 5.75, the coefficient on the immigrant dummy variable. The gap in the average occupation injury rate also declines, from about 30.86 injuries per 10,000 workers to 10.69 . The difference in the average industry fatality rate declines from 1.79 deaths per 100,000 workers to 0.83 , and the difference in the average occupation fatality rate from about 1.60 to -0.54 (immigrants are in occupations with lower fatality rates, controlling for observable characteristics). All of the significance levels of the immigrant-native differences decline as well compared with the difference in raw means. Only the differences in the occupational injury rate and industry fatality rate are significant below the $10 \%$ level when controlling for differences in education, English ability, and the like. These results thus indicate that differences in observable characteristics can explain much of the overrepresentation of immigrants in riskier jobs.

The results in Table 3 indicate several other patterns in the distribution of workers across risky jobs. Women tend to work in safer industries and occupations, as do older workers. Blacks work in jobs with higher injury rates than whites but lower industry and occupation fatality rates. Individuals of "other race" work in safer jobs than whites, and Hispanics tend to work in jobs

\footnotetext{
${ }^{11}$ The estimated coefficients of the state fixed effects are jointly statistically significant in the regressions. This reflects differences in the distribution of industries and occupations across states. The estimated coefficients of the year fixed effects are significant in some, but not all, specifications and do not show a clear pattern.
} 
with higher injury rates. There is an inverse relationship between education and injury and fatality rates, as suggested by the sample means in Table 2 .

The regression results indicate that workers with worse English ability tend to be in riskier jobs. The difference is most notable for workers who speak no English. One result is somewhat puzzling: workers who speak English well but also speak another language hold less risky jobs than workers who only speak English. This result also appears in the raw sample means (Table 2). If we stratify the data by immigrant status, however, there is no significant difference in job injury and fatality rates between immigrants who speak only English and immigrants who speak English very well, controlling for other characteristics (not shown). ${ }^{12}$ Injury and fatality rates increase monotonically among immigrants as ability to speak English declines from very well to not at all.

Among immigrants, years of U.S. residence is generally negatively associated with job risk, but only the relationship with industry fatality rates reaches statistical significance in Table 3. We caution that the years since migration results capture both assimilation and cohort effects. If earlier cohorts of immigrants were more skilled than recent cohorts, then the negative coefficient on years since migration is biased and is likely too large (too negative). We do not attempt to control for cohort effects because we use only 3 years of data (see Borjas, 1985, for a discussion).

Immigrants are in riskier jobs along a variety of dimensions. Table 4 reports the immigrant-native difference in injury rates by the nature of the injury. The columns labeled "Raw" present differences in sample means, and the columns labeled "Adjusted" present the

\footnotetext{
${ }^{12}$ There is a high degree of multicollinearity between the immigrant variable and the omitted English ability category because natives compose $97 \%$ of the English-only observations. This multicollinearity might drive the result for workers who speak English very well relative to workers who only speak English when the immigrant indicator variable is included in the regressions. Alternatively, immigrant households that speak a non-English language at home but are also fluent in English might be more educated (and hence work in better jobs) than other immigrant households.
} 
estimated coefficients on an immigrant dummy variable in regressions that control for other individual characteristics. The significance levels indicate whether the difference is statistically different from zero. Most of the raw differences indicate that immigrants are in jobs with higher injury rates. Interestingly, immigrants tend to be in riskier occupations more than they are in riskier industries—all of the raw differences are statistically significant for occupation injury rates but only a few for industry injury rates (the overall industry injury rate difference is also not statistically significant). As in Table 3 , observable characteristics can explain much of the gaps. The differences are attenuated (and fewer are statistically significant) when controlling for education, English ability, and the like. The results also indicate that, when controlling for observable characteristics, immigrants are less likely to work in jobs that lead to carpel tunnel syndrome.

\section{Robustness}

We performed a number of other estimations to verify the robustness of the results shown in the tables. Stratifying the data by sex revealed some interesting differences, although we caution that the injury and fatality rates are not sex-specific. The raw immigrant-native differences in injury rates are fairly similar for both men and women (and the gap in occupational injury rates is actually greater for female immigrants than for male immigrants). Foreign-born men work in industries with higher fatality rates than do native-born men, but there is no difference among women. When observable characteristics are controlled for, immigrant women work in industries and occupations with significantly higher injury rates than native-born women, and immigrant men work in industries with higher fatality rates than native-born men.

As discussed earlier, immigrants might work in riskier jobs because they tend to have lower incomes and less wealth. The ACS does not have good measures of wealth, but it does 
have measures of unearned individual income and total family income. We ran the specifications shown in Table 3 with an additional variable measuring either unearned individual income or total family income less the individual's earned income. The estimated coefficients and significance levels for the immigrant dummy variable were similar to those shown in Table 3. As expected, the "other income" variables were negatively associated with job risk.

We also tried controlling for the fraction of workers in an industry or occupation who are members of a union or the fraction covered by union representation. ${ }^{13}$ The immigrant-native differences in job risk were slightly larger in magnitude (and more statistically significant) when controlling for unionization rates except for the occupation fatality rates results, which were unchanged. The unionization rate variables were typically positively associated with job risk, indicating that worse jobs have higher unionization rates.

Immigrants who are naturalized citizens might be less likely to hold risky jobs than other immigrants. Our main results do not include an indicator variable for naturalized citizen status because it would be highly correlated with years in the U.S. (and, to a lesser extent, with English ability). If we do include a citizen indicator variable, the results suggest that naturalized citizens work in industries with lower fatality rates than other immigrants. There is little change in the other estimated coefficients in the regression. Naturalized citizen status is not significantly associated with industry or occupation injury rates or occupation fatality rates.

A final concern about our results is multicollinearity between the immigrant, years in U.S., and English ability variables. Multicollinearity can result in larger standard errors (and lower significance levels) or coefficients with the wrong sign or an implausible magnitude. We experimented with running the regressions with only one of those variables (or sets of variables,

\footnotetext{
${ }^{13}$ The union membership and representation data are averages during 2003-2005 from the Bureau of Labor Statistics. The data are available for a total of 22 occupations and 25 industries. The ACS does not include individuals' union status.
} 
in the case of English ability) instead of all three. If only the immigrant dummy variable is included (along with the controls for gender, age, and the like), the coefficients on the immigrant variable are similar to those in Table 3 except that immigrants are significantly more likely than natives to work in industries with higher injury rates. When only years of U.S. residence is included, that variable is not significantly associated with job risk except for occupation injury rates, where the coefficient is positive. When only the measures of English ability are included, we find results similar to those reported for the other variables in Table 3 . In the industry fatality rate specification, the estimated coefficients for the variables for speaking English not well and not at all become statistically significant while the estimated coefficient for the speaking English very well variable is not significant.

\section{CONCLUSION}

This paper examined whether immigrants work in riskier jobs, as measured by injury and fatality rates, than natives. The results clearly indicate that immigrants work in more dangerous industries and occupations. The simple immigrant-native difference in average industry fatality rates is 1.79 deaths per 100,000 workers. Evaluated at 20 million (approximately the number of immigrants employed in 2005), this implies excess mortality of 358 immigrants per year compared to the number of deaths if immigrants had the same distribution across industries as natives. The simple difference in average occupation fatality rates is slightly smaller (1.60), which implies an excess of 320 deaths each year. The simple difference in average industry injury rates of 8.19 per 10,000 workers implies an excess of 16,380 nonfatal injuries involving at least one day away from work among immigrants while the difference in average occupation injury rates of 30.86 per 10,000 workers implies an excess of about 61,720 injuries among immigrants annually. 
These calculations, like all of the findings here, assume that fatality rates within industries and occupations apply equally to natives and immigrants. If immigrants actually experience higher fatality rates within industries and occupations than natives, all of our results are underestimates. Individual-level data on work-related fatalities and injuries that include information on nativity are needed to further examine this issue. Such data would also improve the goodness-of-fit of the models estimated here. Data on fatalities and injuries by industry and occupation jointly also would give a more accurate picture of relative job risks if immigrants and natives hold different occupations within industries.

Our results indicate that differences in observable characteristics, such as English ability and education, play important roles in why immigrants tend to work in riskier jobs. Workers' ability to speak English is inversely related to their industry injury and fatality rate, indicating that immigrants who speak English fluently work in safer jobs. The CDC (2008) attributed the high number of work-related deaths among foreign-born Hispanics in part to inadequate knowledge of safety hazards and inadequate training and supervision of workers, often exacerbated by language and literacy problems. Our findings bolster such calls for more safety training in languages other than English (National Research Council 2003). McHugh, Gelatt, and Fix (2007) estimate that about 750,000 immigrants, or about $2.5 \%$ of the adult foreign-born population, are illiterate. This suggests that simply posting safety instructions in languages other than English would not be sufficient to eliminate disparities in workplace risks. Instead, safety regulations might need to require posters with pictures.

The findings here raise a number of intriguing questions. Previous research using similar methods but earlier data does not find that immigrants work in industries with higher injury or fatality rates (Berger and Gabriel 1991; Hamermesh 1998). Future research should examine why there now appears to be more sorting of immigrants into riskier jobs. Likely reasons include a 
relative decline in immigrants' skills, unprecedented immigrant inflows and the construction boom. Determining whether immigrants face greater risks than natives within specific occupations is also an interesting research area. Whether immigrant inflows affect working conditions, with larger influxes possibly leading to downgrading of conditions and more injuries and workplace deaths, is yet another key area for future work. A final interesting issue is whether immigrants earn the same compensating differential—if any — as natives for working in risky industries and occupations. If immigrants are more willing to accept risky jobs because they underestimate workplace risks due to a lack of information, then they might not earn the same compensating differential as natives and some form of government intervention might be warranted. 


\section{REFERENCES}

Antecol, H. and K. Bedard. 2006. "Unhealthy Assimilation: Why Do Immigrants Converge to American Health Status Levels?” Demography 43:337-360.

Azaroff, L.S., C. Levenstein, and D.H. Wegman. 2002. “Occupational Injury and Illness Surveillance: Conceptual Filters Explain Underreporting.” American Journal of Public Health 92:1421-1429.

Bean, F.D., R. Corona, R. Tuirán, and K.A. Woodrow-Lafield. 1998. "The Quantification of Migration between Mexico and the United States.” Pp. 1-90 in Migration between Mexico and the United States, Binational Study, Vol.1, edited by Mexican Ministry of Foreign Affairs and U.S. Commission on Immigration Reform. Austin: Morgan Printing.

Bean, F.D., L.B.Lowell, and L.J.Taylor. 1988. "Undocumented Mexican Immigrants and the Earnings of Other workers in the United States.” Demography 25:35-52.

Bender, K.A., H.A. Mridha, and J. Peoples. 2006. "Risk Compensation for Hospital Workers." Industrial and Labor Relations Review 59:226-242.

Berger, M.C. and P.E. Gabriel. 1991. "Risk Aversion and the Earnings of US Immigrants and Natives." Applied Economics 23:311-318.

Boden, L.I. and A. Ozonoff. 2008. “Capture-Recapture Estimates of Nonfatal Workplace Injuries and Illnesses." Journal of Epidemiology 18:500-506.

Bonin, H., A. Constant, K. Tatsiramos, and K.F. Zimmerman. 2006. "Ethnic Persistence, Assimilation and Risk Proclivity.” IZA Discussion Paper 2537, December.

Bonin, H., A. Constant, K. Tatsiramos, and K.F. Zimmerman. 2008. "Native-Migrant Differences in Risk Attitudes." Forthcoming in Applied Economics Letters.

Borjas, G.J. 1985. "Assimilation, Changes in Cohort Quality, and the Earnings of Immigrants." Journal of Labor Economics 3:463-489. 
Bureau of Labor Statistics. 2006. "National Census of Fatal Occupational Injuries in 2005." Available online at ftp://ftp.bls.gov/pub/news.release/cfoi.txt.

Census Bureau. 2006. "Educational Attainment in the United States: 2006." Available online at http://www.census.gov/population/www/socdemo/education/cps2006.html (Table 10).

Centers for Disease Control and Prevention (CDC). 2008. "Work-Related Injury Deaths Among Hispanics—United States, 1992-2006.” Mortality and Morbidity Weekly Report 57:597-600.

Chan, S. 2006. "Fatal Construction Accidents in the City Rise Sharply Over 12 Months." New York Times, November 22, p. C13.

Cobb-Clark, D. and V. Hildebrand. 2006. "The Wealth and Asset Holdings of U.S.-Born and Foreign-Born Households: Evidence from the SIPP Data." Review of Income and Wealth $52: 17-42$.

Compa, L. and J. Fellner. 2005. “Meatpacking's Human Toll.” Washington Post, August 3, p A19.

Cornwell, D.D.F. 2006. "Naturalization Rate Estimates: Stock Vs. Flow." Fact Sheet, Department of Homeland Security. Available online at http://www.dhs.gov/xlibrary/assets/statistics/publications/ois_naturalizations_fs_2004.pdf.

Dong, X. and J.W. Platner. 2004. “Occupational Fatalities of Hispanic Construction Workers from 1992 to 2000.” American Journal of Industrial Medicine 45: 45-54.

Fletcher, L.E., P. Pham, E. Stover, and P. Vinck. 2006. "Rebuilding after Katrina: A PopulationBased Study of Labor and Human Rights in New Orleans.” International Human Rights Clinic, Boalt Hall School of Law, University of California, Berkeley.

Franklin, S. and D. Little. 2006. 'Cabbies, Clerks Put Lives on the Line: Immigrants' Top Cause of Death on the Job: Homicide." Chicago Tribune, October 8, p. 1. 
Grieco, E. 2003. "English Abilities of the US Foreign-Born Population.” Migration Information Source. Available online at http://www.migrationinformation.org/USFocus/display.cfm?ID=84.

Hamermesh, D.S. 1998. "Immigration and the Quality of Jobs." Pp. 75-106 in Help or Hindrance? The Economic Implications of Immigration for African Americans, edited by D.S. Hamermesh and F.D. Bean. New York: Russell Sage Foundation.

Hanson, G.H. 2006. "Illegal Migration from the United States to Mexico.” Journal of Economic Literature 44:869-924.

Hoefer, M., N. Rytina, and C. Campbell. 2007. "Estimates of the Unauthorized Immigrant Population Residing in the United States: January 2006.” Fact Sheet, Department of Homeland Security. Available online at http://www.dhs.gov/xlibrary/assets/statistics/publications/ill_pe_2006.pdf.

Loh, K. and S. Richardson. 2004. "Foreign-born Workers: Trends in Fatal Occupational Injuries, 1996-2001.” Monthly Labor Review 127(6):42-53.

Mather, M., K.L. Rivers, and L.A. Jacobsen. 2005. "The American Community Survey.” Population Bulletin 60(3):1-20.

McFadden, R.D. and N. Schweber. 2007. "Brothers Had Concern with Scaffold, Relative Says." New York Times, December 9, p 43.

McHugh, M., J. Gelatt, and M. Fix. 2007. “Adult English Language Instruction in the United States: Determining Need and Investing Wisely.” Mimeo, Migration Policy Institute, July. Available online at http://www.migrationpolicy.org/pubs/NCIIP_English_Instruction073107.pdf.

Mehta, C., N. Theodore, I. Mora, and J. Wade. 2002. “Chicago’s Undocumented Immigrants: An Analysis of Wages, Working Conditions, and Economic Contributions." University of 
Illinois at Chicago Center for Urban Economic Development. Available online at http://www.uic.edu/cuppa/uicued/npublications/recent/undoc_full.pdf.

National Research Council. 2003. Safety is Seguridad. Washington, DC: National Academies Press.

National Institute for Occupational Safety and Health (NIOSH). 2005. "Hispanic Youth Dies in Densifier at a Plastics Recycling Plant.” Hispanic Fatality Investigation Reports. Available online at http://www.cdc.gov/niosh/face/In-house/full200505.html.

National Institute for Occupational Safety and Health (NIOSH). 2007. "Migrant Farm Worker Dies From Heat Stroke While Working on a Tobacco Farm.” Hispanic Fatality Investigation Reports. Available online at http://www.cdc.gov/niosh/face/In-house/full200604.html.

Passel, J.S. 2006. "The Size and Characteristics of the Unauthorized Migrant Population in the U.S.” Pew Hispanic Center Research Report. Available online at http://pewhispanic.org/files/reports/61.pdf.

Pransky, G., et al. 2002. "Occupational Risks and Injuries in Non-Agricultural Immigrant Latino Workers.” American Journal of Industrial Medicine 42:117-123.

Richardson, S. 2005. "Fatal Work Injuries among Foreign-Born Hispanic Workers.” Monthly Labor Review Virtual Essay. Available online at http://www.bls.gov/opub/mlr/2005/10/ressum.pdf.

Richardson, S., J. Ruser, and P. Suarez. 2003. "Hispanic Workers in the United States: An Analysis of Employment Distributions, Fatal Occupational Injuries, and Non-fatal Occupational Injuries and Illnesses." Pp. 43-82 in Safety is Seguridad. Washington, DC: National Academies Press.

Rosen, S. 1986. "The Theory of Equalizing Differences.” Pp. 641-692 in Handbook of Labor Economics, edited by O. Ashenfelter and R. Layard. Amsterdam: North Holland. 
Sandy, R. and R.F. Elliott. 1996. "Unions and Risk: Their Impact on the Level of Compensation for Fatal Risk.” Economica 63:291-309.

Scherzer, T., R. Rugulies, and N. Krause. 2005. "Work-Related Pain and Injury and Barriers to Workers' Compensation Among Las Vegas Hotel Room Cleaners." American Journal of Public Health 95:483-488.

Seminario, P. 2007. “Is OSHA Working for Working People?" Testimony before the Senate Employment and Worker Safety Subcommittee. Available online at http://www.help.senate.gov/Hearings/2007_04_26/Seminario.pdf.

Sincavage, J.R. 2005. "Fatal Occupational Injuries among Asian Workers." Monthly Labor Review 128(10):49-55.

Smith, R.S. 1979. "Compensating Wage Differentials and Public Policy: A Review.” Industrial and Labor Relations Review 32:339-352.

Viscusi, W.K. 1978. "Wealth Effects and Earnings Premiums for Job Hazards." Review of Economics and Statistics 60:408-416.

Viscusi, W.K. 1993. “The Value of Risks to Life and Health.” Journal of Economic Literature 31:1912-1946. 
Figure 1

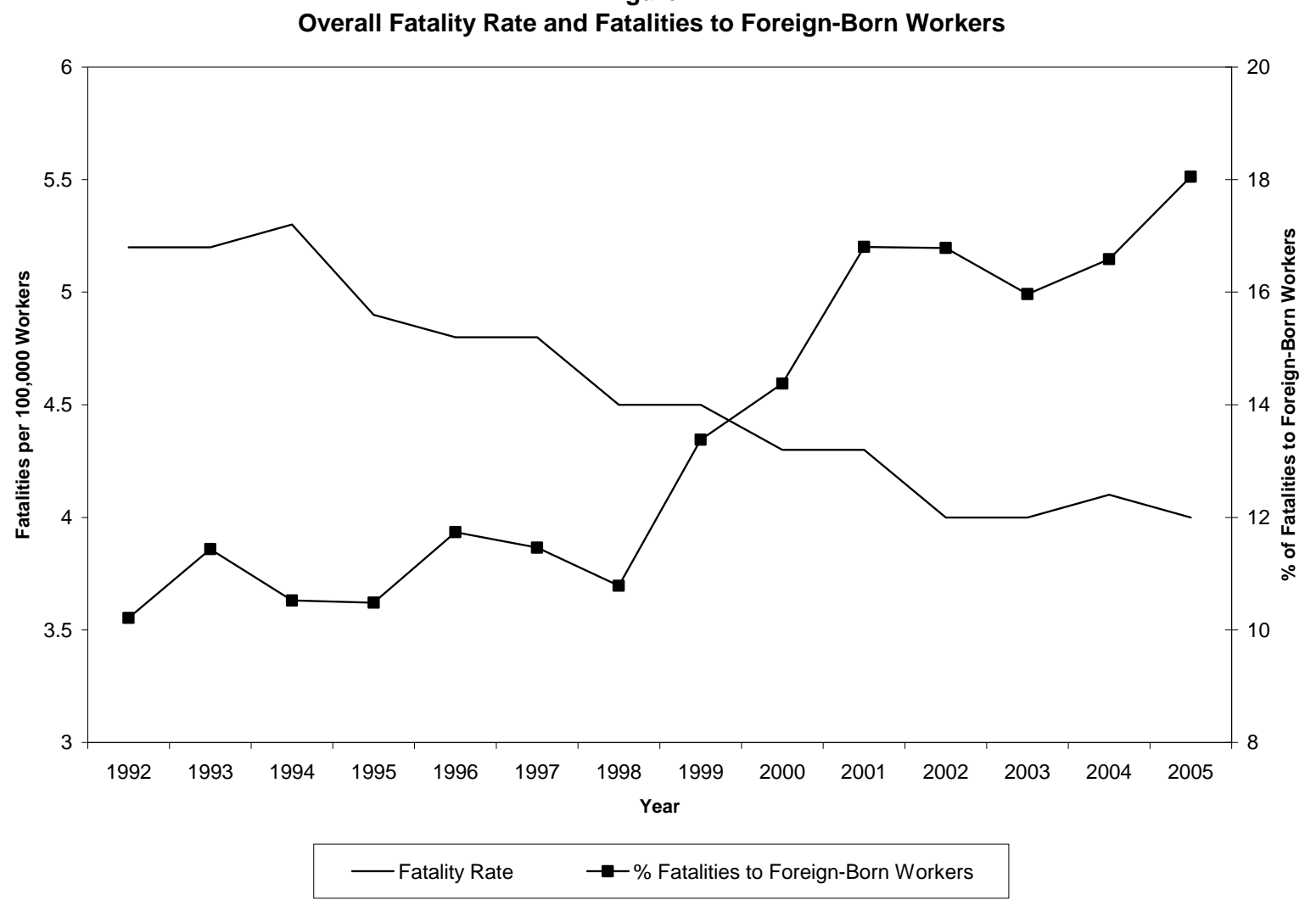


Table 1

Descriptive Statistics for ACS Sample

\begin{tabular}{|c|c|c|c|c|}
\hline \multirow[b]{2}{*}{ Variable } & \multicolumn{2}{|c|}{ Natives } & \multicolumn{2}{|c|}{ Immigrants } \\
\hline & Mean & $\mathrm{SD}$ & Mean & $\mathrm{SD}$ \\
\hline \multicolumn{5}{|l|}{ Individual characteristics: } \\
\hline Female & 0.47 & 0.50 & 0.39 & 0.49 \\
\hline Age & 39.13 & 13.48 & 38.44 & 11.94 \\
\hline Married & 0.53 & 0.50 & 0.62 & 0.48 \\
\hline Divorced, widowed, separated & 0.16 & 0.37 & 0.12 & 0.32 \\
\hline Never married & 0.31 & 0.46 & 0.26 & 0.44 \\
\hline White (non-Hispanic) & 0.81 & 0.40 & 0.18 & 0.38 \\
\hline Black (non-Hispanic) & 0.11 & 0.31 & 0.08 & 0.27 \\
\hline Other race (non-Hispanic) & 0.02 & 0.14 & 0.24 & 0.42 \\
\hline Hispanic & 0.07 & 0.25 & 0.51 & 0.50 \\
\hline No high school diploma & 0.10 & 0.31 & 0.32 & 0.47 \\
\hline High school diploma & 0.31 & 0.46 & 0.24 & 0.43 \\
\hline Some college & 0.33 & 0.47 & 0.19 & 0.39 \\
\hline College degree & 0.25 & 0.43 & 0.25 & 0.43 \\
\hline Years in U.S. & -- & -- & 15.71 & 11.40 \\
\hline Speaks only English at home & 0.93 & 0.25 & 0.15 & 0.36 \\
\hline Speaks English very well & 0.06 & 0.23 & 0.32 & 0.47 \\
\hline Speaks English well & 0.007 & 0.083 & 0.21 & 0.41 \\
\hline Speaks English not well & 0.004 & 0.062 & 0.22 & 0.41 \\
\hline Speaks English not at all & 0.001 & 0.025 & 0.10 & 0.30 \\
\hline $\mathrm{N}$ & \multicolumn{2}{|l|}{$1,492,416$} & \multicolumn{2}{|l|}{215,223} \\
\hline \multicolumn{5}{|l|}{ Injury and fatality rates: } \\
\hline Industry injury rate & 140.55 & 87.99 & 148.74 & 84.92 \\
\hline Occupation injury rate & 108.83 & 118.50 & 139.69 & 129.15 \\
\hline Industry fatality rate & 4.71 & 9.57 & 6.50 & 12.19 \\
\hline Occupation fatality rate & 5.93 & 56.79 & 7.54 & 66.95 \\
\hline
\end{tabular}

Note: Observations are weighted using the person weights in the ACS. The sample only includes individuals aged 16 and older who are employed in the private sector and not self-employed. Injury rates are per 10,000 workers, and fatality rates per 100,000 workers. 
Table 2

Average Injury and Fatality Rates by Education and English Ability

\begin{tabular}{lcccc}
\hline Variable & $\begin{array}{c}\text { Industry } \\
\text { Injury Rate }\end{array}$ & $\begin{array}{c}\text { Occupation } \\
\text { Injury Rate }\end{array}$ & $\begin{array}{c}\text { Industry } \\
\text { Fatality Rate }\end{array}$ & $\begin{array}{c}\text { Occupation } \\
\text { Fatality Rate }\end{array}$ \\
\hline No high school diploma & 166.86 & 175.72 & 8.26 & 10.45 \\
High school diploma & 158.40 & 146.12 & 6.09 & 7.47 \\
Some college & 140.01 & 102.86 & 4.23 & 5.03 \\
College degree & 110.63 & 53.74 & 2.84 & 3.74 \\
Speaks only English at home & 140.51 & 108.46 & 4.69 & 5.90 \\
Speaks English very well & 133.43 & 100.80 & 4.38 & 5.38 \\
Speaks English well & 152.53 & 145.42 & 6.36 & 7.44 \\
Speaks English not well & 166.35 & 184.35 & 8.53 & 9.88 \\
Speaks English not at all & 176.16 & 210.27 & 12.46 & 13.69 \\
\hline
\end{tabular}

Note: Injury rates are per 10,000 workers, and fatality rates per 100,000 workers. 
Table 3

Relationship between Individual Characteristics and Injury and Fatality Rates

\begin{tabular}{|c|c|c|c|c|c|c|c|c|}
\hline \multirow[b]{2}{*}{ Variable } & \multicolumn{2}{|c|}{ Industry Injury Rate } & \multicolumn{2}{|c|}{ Occupation Injury Rate } & \multicolumn{2}{|c|}{ Industry Fatality Rate } & \multicolumn{2}{|c|}{ Occupation Fatality Rate } \\
\hline & Coeff. & SE & Coeff. & $\mathrm{SE}$ & Coeff. & $\mathrm{SE}$ & Coeff. & $\mathrm{SE}$ \\
\hline Immigrant & 5.747 & 4.384 & $10.687^{\dagger}$ & 5.985 & $0.828^{*}$ & 0.404 & -0.535 & 1.060 \\
\hline Female & $-28.986^{*}$ & 11.679 & $-64.315 * *$ & 14.611 & $-4.197 * *$ & 1.064 & $-7.265^{* *}$ & 1.548 \\
\hline Age & $1.784 *$ & 0.746 & $2.036^{*}$ & 0.794 & $0.143^{*}$ & 0.072 & $0.137^{*}$ & 0.063 \\
\hline $\mathrm{Age}^{2}$ & $-0.019 *$ & 0.008 & $-0.024 * *$ & 0.008 & $-0.002 * *$ & 0.001 & $-0.002 *$ & 0.001 \\
\hline Married & 1.741 & 2.343 & -3.294 & 2.679 & $0.422 *$ & 0.202 & $0.675^{*}$ & 0.239 \\
\hline Divorced, widowed, separated & d $6.036^{* *}$ & 1.750 & $5.061 * *$ & 1.890 & $0.561 * *$ & 0.200 & $0.657 * *$ & 0.176 \\
\hline Black & 9.058 & 6.485 & $15.507 *$ & 7.450 & $-0.723^{\dagger}$ & 0.421 & $-1.526^{*}$ & 0.742 \\
\hline Other race & $-11.428 * *$ & 4.313 & $-11.932 * *$ & 3.707 & $-1.639 * *$ & 0.451 & $-1.526^{* *}$ & 0.742 \\
\hline Hispanic & $5.218 * *$ & 1.644 & $11.316^{* *}$ & 2.809 & 0.360 & 0.364 & -0.013 & 0.515 \\
\hline No high school diploma & 6.370 & 4.101 & $17.008 * *$ & 4.661 & $1.353^{*}$ & 0.622 & $2.215^{*}$ & 1.081 \\
\hline Some college & $-15.442 * *$ & 4.173 & $-36.735 * *$ & 5.844 & $-1.511 * *$ & 0.417 & $-1.955^{* *}$ & 0.539 \\
\hline College degree & $-45.605 * *$ & 9.211 & $-87.597 * *$ & 13.265 & $-3.140 * *$ & 0.876 & $-3.703 * *$ & 1.179 \\
\hline Years in U.S. & -0.172 & 0.141 & -0.211 & 0.153 & $-0.025^{\dagger}$ & 0.013 & 0.026 & 0.047 \\
\hline Speaks English very well & -2.009 & 1.431 & $-5.796^{* *}$ & 1.525 & $-0.351^{\dagger}$ & 0.196 & $-0.386^{*}$ & 0.185 \\
\hline Speaks English well & $5.124^{*}$ & 2.574 & $15.096 * *$ & 2.702 & 0.369 & 0.336 & 0.244 & 0.261 \\
\hline Speaks English not well & 6.936 & 4.802 & $29.478 * *$ & 7.402 & 1.186 & 0.738 & 1.139 & 0.787 \\
\hline Speaks English not at all & $11.064^{*}$ & 5.149 & $42.687 * *$ & 14.478 & 4.329 & 2.871 & $4.199^{\dagger}$ & 2.391 \\
\hline Adjusted $\mathrm{R}^{2}$ & 0.093 & & 0.208 & & 0.090 & & 0.006 & \\
\hline$\underline{\mathrm{N}}$ & $1,707,639$ & & $1,699,721$ & & $1,706,030$ & & $1,704,027$ & \\
\hline
\end{tabular}


${ }^{\dagger} \mathrm{p}<0.1{ }^{*} \mathrm{p}<0.05 ; * * \mathrm{p}<0.01$ Note: Regressions also include controls for state and survey year. Observations are weighted using the person weights in the ACS. Standard errors are clustered on industry or occupation. 


\section{Table 4}

Immigrant-Native Differences in Injury Rates by Nature of the Injury

\begin{tabular}{|c|c|c|c|c|}
\hline \multirow[b]{2}{*}{ Nature of Injury } & \multicolumn{2}{|c|}{ Industry Injury Rate } & \multicolumn{2}{|c|}{ Occupation Injury Rate } \\
\hline & Raw & Adjusted & Raw & Adjusted \\
\hline Sprains and strains & 1.054 & 1.751 & $10.348 * *$ & 4.093 \\
\hline Fractures & 0.866 & 0.635 & $2.440 *$ & 0.966 \\
\hline Cuts and punctures & $2.411 * *$ & $1.475^{* *}$ & $5.211 * *$ & $2.268^{*}$ \\
\hline Bruises & $0.715^{\dagger}$ & 0.436 & $2.724 * *$ & 0.681 \\
\hline Heat burns & $0.352^{\dagger}$ & $0.305^{\dagger}$ & $0.750^{*}$ & $0.311^{\dagger}$ \\
\hline Chemical burns & $0.131 * *$ & $0.064^{\dagger}$ & $0.308 * *$ & $0.094^{*}$ \\
\hline Amputations & $0.139 *$ & 0.029 & $0.303 * *$ & 0.047 \\
\hline Carpel tunnel syndrome & 0.005 & $-0.105^{*}$ & $0.279 *$ & $-0.124^{*}$ \\
\hline Tendonitis & 0.053 & 0.001 & $0.183 * *$ & 0.007 \\
\hline Multiple traumatic injuries & $0.423^{\dagger}$ & 0.243 & $0.869^{*}$ & 0.148 \\
\hline Pain & 0.388 & 0.244 & $2.283 * *$ & $1.029^{\dagger}$ \\
\hline Back pain & 0.177 & 0.140 & $0.847 * *$ & $0.438^{\dagger}$ \\
\hline All other injuries & 1.677 & 0.999 & $5.203 * *$ & 1.481 \\
\hline
\end{tabular}

${ }^{\dagger} \mathrm{p}<0.1 ; * \mathrm{p}<0.05 ; * * \mathrm{p}<0.01$

Note: Columns labeled "Adjusted" control for other individual characteristics (see Table 3), state and survey year. Observations are weighted using the person weights in the ACS. Significance levels are based on standard errors clustered on industry or occupation. 